Journal of Accident and Emergency Medicine 1995

12, 107-110
Correspondence:

Dr T.A. Farnsworth, Castle Hill Hospital, Cottingham, East Yorkshire HU16 5JQ, UK

\title{
Subjective perception of additional support requirements of elderly patients discharged from accident and emergency departments
}

\author{
T.A. FARNSWORTH, S. WAINE ${ }^{2} \& A$. MCEVOY \\ ${ }^{1}$ Castle Hill Hospital, Cottingham and ${ }^{2}$ York District Hospital, York, UK
}

\section{SUMMARY}

Fifty per cent of elderly patients discharged from accident and emergency (A\&E) departments experience functional deterioration and increased dependence; $5.6 \%$ require readmission within 14 days. ${ }^{1}$ Discharge is often to inadequate community support. $^{2}$ Functional assessment by A\&E department staff may identify patients at greatest risk. The predictive ability of 25 patients aged 75 years or over to identify their additional support requirements following discharge from the A\&E department was evaluated retrospectively using interview questionnaires 10-20 days after discharge. A total of 23 patients, of mean age 79.3 years, were interviewed. Six patients expressed concern both about coping at home and about needing extra support; four of the nine patients who recruited additional help were in this group $(P=0.239$; n.s.). There was no correlation between additional support needed and patients living alone ( $P=0.302$; n.s.), dependent relative ( $P=0.325$; n.s.) or existing domiciliary support $(P=0.197$; n.s.). All patients were satisfied with their management, and of the six who expressed concern about being able to cope at home, none informed A\&E staff. Patients' perception is an unreliable indicator of their need for additional help and their ability to manage at home after discharge from A\&E departments. Additional support requirements appear to be unrelated to domestic circumstances.

Key words: additional, discharge, elderly, perception, subjective, support

\section{INTRODUCTION}

As the proportion of elderly people in the population rises, the contribution of older patients to the workload of A\&E departments increases. ${ }^{3}$ The management of older patients makes greater time demands on A\&E staff. ${ }^{4}$ The percentage of patients admitted from A\&E depatments also increases with advancing age. In one study, ${ }^{1}$ only $53 \%$ of patients aged 75 years or over were discharged home, but over $10 \%$ of these patients who had significantly lower pre-morbid functional capabilities, required readmission within 14 days. An increased mortality at 3 months (10\%) has been observed in older patients discharged from A\&E and, on the basis of this and a high rate of return, a lower threshold for admission for elderly patients has been recommended. ${ }^{5}$

Risk factors that predict readmission all appear to be related to pre-attendance functional capability, ${ }^{1}$ and $50 \%$ of elderly patients discharged home experience a deterioration in functional capacity. ${ }^{1.2}$ Patients are also frequently discharged to a domestic situation with inadequate social support, despite increased requirements. ${ }^{2}$ Hence provision of aftercare is as important as hospital treatment. ${ }^{6}$ The importance of a thorough objective functional and social assessment by A\&E staff is therefore well recognized, ${ }^{2}$ but remains extremely difficult to perform accurately in busy units, and the documentation of these factors is known to be inadequate. ${ }^{5}$ Even where such evaluations are made, many elderly patients are still readmitted within $24 \mathrm{~h}^{7}$

This study addresses elderly patients' subjective assessment of their own ability to cope at home, and their perception of their requirements for additional support from any source.

\section{PATIENTS AND METHODS}

Patients were recruited for inclusion in the study from the attendance register at the A\&E reception desk, York District Hospital. Every fourth patient aged 75 years or over discharged from the A\&E department was visited at home by a community 
T.A. Farnsworth et al. sister (SW) (permission having been previously obtained from the patient and their general practitioner) between 10 and 20 days following discharge, and completed an interview questionnaire. This provided data relating to the nature of the presenting problem, personal details, domestic circumstances, pre- and post-morbid self-care capabilities (using the Barthel Index ${ }^{8}$ outlined below), worries concerning ability to cope at home, and pre-discharge perception of and actual requirements for additional support. Patients' satisfaction with the service overall and the attention paid to their ability to cope, by A\&E staff in particular, were also recorded.

Statistical evaluation of the relationships between patient characteristics, their subjective perception of ability to cope and their help requirements, including actual support engaged, were performed using Fisher's exact test.

The Barthel Index is a recognized and approved standard scale used (particularly in medicine for the elderly departments) to evaluate self-care capabilities by means of a points-scored system. The following ten activities of daily living (ADL) are considered; feeding, grooming, dressing, bathing, bladder and bowel function, toilet use, chair/bed transfer, mobility and climbing stairs. A maximum of 20 points is achieved for full independence.

\section{RESULTS}

A total of 23 patients (16 females, and seven males), of mean age 79.3 years (range 75-97 years, median 78 years, S.E.M. 0.989 years) were interviewed at home (two patients were lost to follow-up; one relocated, and the other subsequently refused interview).

The personal details of the patients interviewed are summarized in Table 1. All discharged patients returned to their previous place of residence; one individual was resident in a nursing home. Eleven patients $(48 \%)$ were living alone, seven $(30 \%)$ were living with their spouse and four $(17 \%)$ with other relations (three with a son or daughter, one with a grandchild). Five patients $(22 \%)$ returned home having to care for a dependent relative.

Six patients $(26 \%)$ were receiving a domiciliary support service prior to attending the A\&E department . Four (17\%) of these achieved Barthel ADL scores of $16-17$ out of 20 . The remaining 19 subjects scored a maximum of 20.

Table 2 specifies the diagnoses of all patients
Table 1. Personal and domestic details of patients interviewed following discharge from the A\&E department

\begin{tabular}{lrr}
\hline Characteristic & Number & \\
\hline Total patients & 23 & \\
$\quad$ Female & 16 & $(70 \%)$ \\
$\quad$ Male & 7 & $(30 \%)$ \\
& & \\
Mean age (years) & 79.3 & S.D. 4.8 \\
Age (years) & & \\
$\quad 75-79$ & 15 & $(65 \%)$ \\
$80-84$ & 6 & $(26 \%)$ \\
$>85$ & 2 & $(9 \%)$ \\
& & \\
Living alone & 11 & $(48 \%)$ \\
Living with spouse & 7 & $(30 \%)$ \\
Living with other relatives & 4 & $(17 \%)$ \\
Living in nursing home & 1 & $(5 \%)$ \\
Dependent relative & 5 & $(22 \%)$ \\
Widowed & 8 & $(35 \%)$ \\
Domiciliary support pre-injury & 6 & $(26 \%)$ \\
Pre-injury Barthel score & & \\
20 & 19 & $(83 \%)$ \\
$18-19$ & 0 & \\
$16-17$ & 4 & $(17 \%)$ \\
\hline
\end{tabular}

Table 2. Diagnoses of patients discharged from the A\&E department

\begin{tabular}{lc}
\hline Diagnosis & Number \\
\hline Sprained ankle & $1^{\circ}$ \\
Head injury & 1 \\
Laceration & $3^{\circ}$ \\
Soft tissue injury & $13^{\circ}$ \\
Food poisoning & 1 \\
Road traffic accident & 2 \\
Dog bite & 1 \\
Varicose vein bleed & 1 \\
& \\
Total falls & 17 \\
\hline
\end{tabular}

Dressings were applied in four cases (including sprained ankle). One patient was supplied with a walking stick. No fractures were sustained.

Sustained in falls.

"Two sustained in falls, one primary.

necessitated by the study design to enable direct discharge), all minor injuries. The concerns and additional support requirements (anticipated and actual) are listed in Table 3. All 23 patients expressed complete satisfaction with the service they received, although six had specific worries about their ability to cope at home. Five patients would have liked to notify the A\&E staff about their concerns, although none did so (all stated that this 
Subjective

support needs of elderly discharges

\begin{tabular}{|c|c|c|c|c|}
\hline \multicolumn{3}{|c|}{ Concerns/support needs } & \multicolumn{2}{|c|}{ Number } \\
\hline \multicolumn{3}{|l|}{ Total patients } & 23 & \\
\hline \multicolumn{3}{|c|}{ Were you worried about coping? } & 6 & $(26 \%)$ \\
\hline \multicolumn{3}{|c|}{ Were you asked about coping? } & 0 & \\
\hline \multicolumn{3}{|c|}{ Were A\&E staff aware of your concern? } & 0 & \\
\hline \multicolumn{3}{|c|}{ Would you have liked to discuss your worries? } & 5 & $(22 \%)$ \\
\hline \multicolumn{3}{|c|}{ Did you anticipate needing additional help? } & 6 & $(26 \%)$ \\
\hline \multicolumn{3}{|c|}{ Did you require additional support? } & 9 & $(39 \%)$ \\
\hline \multicolumn{3}{|c|}{ Were you satisfied with the A\&E service? } & 23 & $(100 \%)$ \\
\hline $\begin{array}{l}\text { Patient } \\
\text { characteristic }\end{array}$ & $\begin{array}{c}\text { Additional } \\
\text { support required }\end{array}$ & $\begin{array}{r}\text { No } \\
\text { supp }\end{array}$ & $\begin{array}{l}\text { dditional } \\
\text { t required }\end{array}$ & Comparison \\
\hline Worried about coping & 4 & & 2 & $P=0.239 ;$ n.s. \\
\hline $\begin{array}{l}\text { Anticipated needing } \\
\text { additional support }\end{array}$ & 4 & & 2 & $P=0.239 ;$ n.s. \\
\hline Living alone & 3 & & 6 & $P=0.302 ;$ n.s. \\
\hline Dependent relative & 2 & & 3 & $P=0.325 ;$ n.s. \\
\hline
\end{tabular}

Table 3. Details of patients' concerns and extra support requirements following discharge from the A\&E department

Table 4. Relationship between patients' subjective concerns and their actual help requirements was because they considered them to be 'too busy'). Six patients (26\%) anticipated needing supplementary support after discharge, but nine $(39 \%)$ eventually required such support.

Table 4 shows the anticipated and actual additional support needs of patients within particular categories. Extra help was required by only four $(17 \%)$ of the six patients who considered that this would be necessary (the same six individuals who were worried about their ability to cope), compared to five (22\%) of the 17 patients who thought they could manage without extra support $(P=0.239 ; n . s$.). There were no significant differences between patients living alone compared to those who were not alone $(P=0.302)$, or between the presence compared to the absence of a dependent relative $(P=0.325)$, for either anticipated or actual additional support requirements.

Details of additional help recruited, including the mechanisms of need recognition and arrangement of support, are shown in Table 5. Considerate neighbours enabled two patients to remain otherwise independent, and in five cases there was increased input from the patient's immediate family; one patient stayed temporarily with her daughter for 6 days. Home help assistance arranged by a general practitioner, and temporary nursing home residence precipitated by inability to self-care was required by two individuals. At interview, this extra support was still being provided for four individuals by family (three cases)
Table 5. Additional support recruited by patients discharged from A\&E department

\begin{tabular}{lc}
\hline Details & Number \\
\hline Support agent & 5 \\
Immediate family & 2 \\
Neighbour & 1 \\
Nursing home & 1 \\
Home help & \\
Mode of need identification & 3 \\
Failure to cope & 6 \\
$\quad$ Presumed need on return home & \\
Mode of arrangement & \\
$\quad$ Self/family & 7 \\
General practitioner & 2 \\
\hline
\end{tabular}

\section{DISCUSSION}

A thorough and complete objective assessment of elderly patients prior to discharge from A\&E departments is recognized as being both important and difficult. Questionnaires completed by the A\&E staff, highlighting functional capabilities, may help to minimize inappropriate discharge of older individuals by identifying those who are likely to be unable to cope at home as a result of inadequate support,' although early readmission rates remain high. $^{7}$

In this study, patients' subjective concerns about being able to cope at home following discharge from A\&E departments and their perceptions of 
T.A. Farnsworth et al. their need for supplementary support were inaccurate predictors of their actual ability to manage and the extra help that they did subsequently require. Such data appear to be of little value in identifying those patients who would benefit from additional help, and should not be considered significant factors in determining the recruitment of support services. Similarly, there was no relationship between the requirement for additional support and whether or not the patients lived alone, or the presence or absence of a dependent relative. This indirectly supports the findings of previous studies which have suggested that pre-morbid functional capability and incapacity resulting from the injury are the most important risk factors for elderly readmissions following discharge from A\&E departments.

It is significant that none of the $26 \%$ of patients who were concerned about their ability to cope at home informed the A\&E staff of this, because they perceived them to be too busy, yet all of these patients subsequently expressed complete satisfaction with the service that they received. Although the concerns of patients appear to be of poor predictive value with regard to the requirement for additional support, these anxieties need to be expressed as they may result from inadequate information regarding the injury, and are a potential cause of repeat consultation. Such worries merit discussion both to allay anxiety and to confirm that any advice given, (especially relating to medication) has been understood. Elderly patients in particular need to be questioned specifically about their concerns regarding their ability to cope at home after discharge from A\&E departments. Previous recommendations that elderly individuals discharged from all sources in hospital should be visited by a community liaison officer within $48 \mathrm{~h}$ to establish the need for support services may be of particular relevance to such patients. ${ }^{9}$

We would suggest that the following protocol be applied to all elderly patients attending A\&E departments with minor injuries and subsequently discharged back to their place of residence:

(1) evaluation of pre-admission capabilities;

(2) post-injury ADL assessment;

(3) documentation of any specific concerns regarding inability to cope;
(4) record of additional support arranged prior to discharge;

(5) domiciliary visit by liaison worker within $48 \mathrm{~h}$ to evaluate the success of discharge, including the extra help provided, and to enquire about any problems relating to predischarge concerns recorded in (3).

Whilst this is an exhaustive and time-consuming exercise, recorded data would not only provide a valuable reference source for future episodes, but by potentially minimizing subsequent injury-related complications and identifying cases that need early social intervention, the number of readmissions may be reduced. This is not only beneficial to patients, but also of overall financial advantage to care providers.

\section{REFERENCES}

1. Rowland K., Maitra A.K., Richardson D.A., Hudson K. \& Woodhouse K.W. (1990) The discharge of elderly patients from an accident and emergency department - functional changes and risk of readmission. Age and Ageing 19, 415-418.

2. Currie C.T., Lawson P.M., Robertson C.E. \& Jones A. (1984) Elderly patients discharged from an accident and emergency department - their dependency and support. Archives of Emergency Medicine 1, 205-213.

3. Dove A.F. \& Dave S.H. (1986) Elderly patients in the accident department and their problems. British Medical Journal 292, 808-809.

4. Lowenstein S.R., Crescent C.A., Kern D.C. \& Steel K. (1986) Care of the elderly in the emergency department. Annals of Emergency Medicine 15, 528-535.

5. Rosenfield T., Fahey P., Price M. \& Leeder S. (1990) The fate of elderly patients discharged from the Accident and Emergency department of a general teaching hospital. Community Health Studies 14, 365372.

6. Buck M. \& Mills A. (1988) Time to go home. Nursing Times 84, 42-43.

7. Dove A.F., Dave S.H. \& Gerrard E. (1986) The accident department and Age Concern. Health Trends 18, 8688.

8. Wade D.T. \& Collin C. (1988) The Barthel ADL Index: a standard measure of physical disability? International Disability Studies 10, 64-67.

9. Williams E.I. \& Fitton F. (1988) Factors affecting early unplanned readmission of elderly patients to hospital. British Medical Journal 297, 784-787. 